\title{
CONTROL OF THE BLOOD SUGAR LEVEL IN THE NEONATAL PERIOD
}

\author{
BY \\ JAMES W. FARQUHAR \\ From the Department of Child Life and Health, University of Edinburgh
}

(RECEIVED FOR PUBLICATION APRIL 23, 1954)

Hypoglycaemia, as judged by adult standards, has been recorded by the majority of those responsible for approximately $\mathbf{5 0}$ papers on the subject of blood sugar levels in newborn infants. Most of these studies may be criticized for one or other of the following reasons. Levels vary not only between individual babies but from day to day in the same infants; this fluctuation is most marked in the first hours of life so that the range of 'normal' from birth on each day thereafter must be found and cannot be determined for the newborn period by considering the values in infants of different ages. The blood sugar has been determined after fasting periods which have been not only of varying length but also shorter than would be acceptable even in a routine laboratory investigation. The chemical method or the way in which it has been employed has been at times unsatisfactory.

Among the well-known investigations are those of Köhler (1932), McKittrick (1940), Norval, Kennedy and Berkson (1949), Reis, De Costa and Allweiss (1950), Pedersen (1952), Creery and Parkinson (1953) and Komrower (1954). Of these the last three publications were concerned only with the first neonatal day, Norval's paper failed to appreciate the changes that might occur in the first hours while Reis et al. in an otherwise comprehensive study made no reference to the accuracy of their method. Of those who followed serial levels, Kohler regarded five and a half hours as a satisfactory fasting period, McKittrick accepted a minimum of three and a half, Norval four hours and Reis et al. did not mention it.

Previous workers have agreed, however, that individual babies show quite wide fluctuations while there is great variation on any one day in a group accepted as normal. Sugar levels tend to fall for some hours before becoming stabilized and the lowest figures are recorded on the second and third days when a gradual rise is usual. None of the serial studies so far, however, has taken a fast which would be acceptable at any other age, the reason probably being an unwillingness to interfere with the infant's feeding routine.

Economy in blood is essential in small babies and this has led to single specimens only being analysed. Very little contamination or deterioration of reagents introduces quite wide errors and duplicate specimens are therefore more reliable. It is true also that the scrupulous conditions applied to testing a method's accuracy may not always be employed in later use. Wooton and King (1953) have shown how scattered the results on a known glucose solution may be when analysed in different laboratories while Lehmann and Silk (1952) have pointed out the difficulties in colour development and stability when duplicate analyses were made by the method of Folin and Wu or its modifications. King and Garner (1947) have also had difficulty with their modifications of this method while the familiar Folin and Wu tube is a confession of the method's instability. Many of the investigators of neonatal sugar levels have relied, however, on single determinations by this method.

\section{Control of Carbohydrate Metabolism}

The elucidation of carbohydrate control in the mature organism is incomplete but the present knowledge of it has been stated by Long (1952) and Talbot, Sobel, McArthur and Crawford (1952). - From these reviews of a very great deal of animal and human investigation it is apparent that the sugar-fat-nitrogen hormone (11-17 oxycorticosteroids) plays an important part in maintaining the blood sugar level. From Fig. 1 it may be seen that the sugar-fat-nitrogen hormone accelerates the production of glucose from non-carbohydrate sources (fat and protein) while retarding its oxidation in the tissues. Deficiency of this hormone results in hypoglycaemia, increased tolerance of sugar and sensitivity to insulin, while an increased production leads to directly opposite conditions. The sugarfat-nitrogen hormone is produced by the adrenal 
cortex as a result of stimulation by endogenous corticotrophin (A.C.T.H.) from the anterior pituitary and this accounts for the diabetogenic effects of therapeutic A.C.T.H., for the decreased sugar tolerance in Cushing's syndrome and for the hypoglycaemia of Addison's disease.

Insulin antagonizes the sugar-fat-nitrogen hormone by stimulating glycogenesis and by conversion of glucose into fat and protein. It is now believed that the pancreatic $\beta$ cells respond not to a pancreatropic pituitary hormone but simply to the blood sugar level and this, should it be raised, may increase insulin production and then exhaust it.

In short, it appears that the homeostatic mechanism by which the blood glucose is maintained at a given level is largely an interplay between the pituitary-adrenal axis and the pancreas, the liver being both fuel reserve and furnace while the hormones form the thermostat (Soskin, 1941).

\section{The Neonatal Adrenal}

The adrenal glands of the newborn are much larger in proportion to body weight than at any other age. This is due almost entirely to the large cortex which has a light coloured, narrow exterior and a wide, dark inner zone. Although differentiation into glomerular, fascicular and reticular zones is not so clear as in the adult (Potter, 1952), careful morphological studies led Blackman (1946) to conclude that the foetal cortex corresponded in many ways to the reticular cells of the adult gland and the term 'foetal reticular zone' was proposed. This zone accounts for $85 \%$ of the entire neonatal cortex (Swinyard, 1943). Grollman (1936), Reichstein (1936) and Howard (1937) believed it to produce androgenic substances because of its similarity to the zone persisting in the adrenogenital syndrome but Gersh and Grollman (1939) have since failed to demonstrate androgenic activity in the cells while Blackman (1946) did find differences between the reticular zones of normal infants and those with adrenogenitalism.

The foetal cortex is present early in development, becomes increasingly noticeable from the twentyfifth week of gestation (Clatworthy and Anderson, 1944), and grows immensely towards the termination of pregnancy (Swinyard, 1943).

As unexplained as its development and function is the dramatic involution of the foetal reticular zone which follows immediately upon birth and is independent of maturity so that separation from the mother and the beginning of extra-uterine existence seem to be the only possible causes. Potter (1952) believed that the greatest changes were complete in the neonatal period while McNeill (1947) stated that the foetal cortex had disappeared by the end of the third week. Other phenomena in the newborn, such as enlargement of the breasts, lactation, congestion and enlargement of the external genitals and uterus, involute also with the start of an independent existence, and it seems at least likely that the changes in the adrenal cortex also represent the influence of maternal hormones. If so, then the hormone most likely to affect this gland would be corticotrophin.

O'Donnell, Fajans and Weinbaum (1951) have described the adrenal changes which occur when corticotrophin is given therapeutically. Lipoid is reduced in all zones while there is narrowing of the outer (zona glomerulosa) and hypertrophy of the two inner (zona fasciculata and zona reticulosa) zones. Some of these changes are still visible 23 days after the last dose of corticotrophin but the glands are normal in six months-findings which compare suggestively with the adrenals of newborn infants. The lipoid of the adrenal cortex is believed to be some kind of indicator of its steroid activity (Selye, 1946a; Sayers, Sayers, Fry, White and Long, 1944). Potter records that there is little lipoid in the adrenal cortex at birth and this corresponds to the findings of O'Donnell et al. (1951) above after giving corticotrophin. Selye (1946a and b) found that the adrenal lipoid was readily affected by disease and that those who have died of acute disease possessed much less than those who had succumbed to a chronic illness. Very similare observations were made by Sayers and Sayers (1948) while Weltman (1913) in a group described as the 'hyperacutely dead' found plenty of lipoid substance.

The fact is that any newborn who has died has already suffered stress sufficient to change the lipoid content of the cortex while the enormous adaptation required to establish extra-uterine existence must make a great call on the adrenals. Histological examination bears no relationship necessarily to their normal function in the newborn for, short of infanticide, there is no way of securing a normal gland. Because of this, studies should be made rather of adrenal cortical function in normal and abnormal live infants.

The fact that operative procedures, cold, haemorrhage and other stimuli result in eosinopenia has been recognized for some time and Selye (1949) included this as part of the alarm reaction. Hills, Forsham and Finch (1948) demonstrated that corticotrophin and compound F produced a decrease in the numbers of circulating eosinophils and have shown that the stimuli required to reproduce it are stress conditions, while Thorn, Forsham, Prunty and Hills (1948) made it clear that the adrenal cortex was essential if eosinolysis was to occur and that the sugar-fat-nitrogen hormone was responsible for it 
TABLE 1

EOSINOPHIL RANGE IN NORMAL NEWBORN INFANTS

\begin{tabular}{|c|c|c|c|c|c|c|}
\hline & Day 1 & Day 2 & Days 3-5 & Days 6-8 & Days 8-10 & Days 9-11 \\
\hline $\begin{array}{l}\text { Forkner (1929) } \\
\text { Klein and Hanson (1950) }\end{array}$ & $\begin{array}{c}0-895 \\
(429) \\
78-988 \\
(359=47)\end{array}$ & $\begin{array}{l}75-1.100 \\
(420=43)\end{array}$ & $\begin{array}{c}168-1,110 \\
(600)\end{array}$ & $\begin{array}{c}160-727 \\
(411)\end{array}$ & $\begin{array}{c}63-483 \\
(268=42)\end{array}$ & $\begin{array}{c}205-873 \\
(417)\end{array}$ \\
\hline
\end{tabular}

Mean values in brackets.

(Fig. 1). Several studies of the numbers of circulating eosinophils in newborn infants have been made (Table 1). When considering the means of the ranges

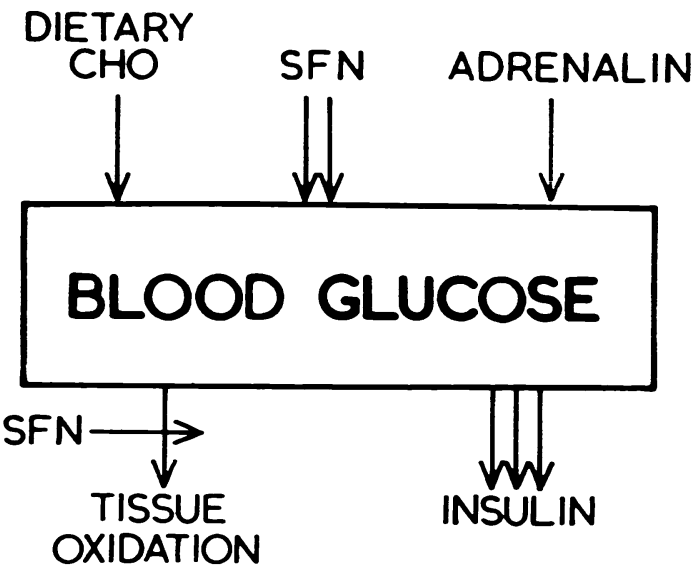

\section{SFN $\uparrow$ EOSINOPHILS \\ SFN $\downarrow$ EOSINOPHILSA}

Fig. 1.-Diagrammatic representation of carbohydrate control (after Talbot). given it appears from both series that the values rise in the first few days of life and then progressively fall although it must be acknowledged that the scatter is so wide that the significance of the mean is doubtful. The values are, however, above the mean for adults. Burrell (1953) recorded graphically the mean of eosinophil counts in full-term infants as rising from birth to 1 week and becoming stabilized at that point.

Svensgaard (1931-32) showed glucose tolerance to be greater in the first few days than in the second week. Day (1948) studied the 11-17 oxycorticosteroids in the urine of newborn infants and found little to suggest significant deficiency, but Venning (1950), assessing the response of the newborn adrenals to corticotrophin by measuring eosinopenia, 17-ketosteroids and 11-17 oxycorticosteroids, found that the glands of 2-day-old infants were less responsive than those of 9-day-olds. This was substantiated independently by Klein $(1950,1951)$.

Talbot, Zygmuntowicz, Wood and Christo (1950) reported, too, that corticoid excretion per unit of body surface was constant throughout life except in the first few days when it was low. Klein, Fortunato and Papadotos (1954) have shown by direct estimation of blood corticoids that these are

TABLE 2

SERIAL READINGS OF PARALLEL BLOOD SUGAR AND EOSINOPHIL LEVELS IN NORMAL FULL-TERM NEWBORN INFANTS

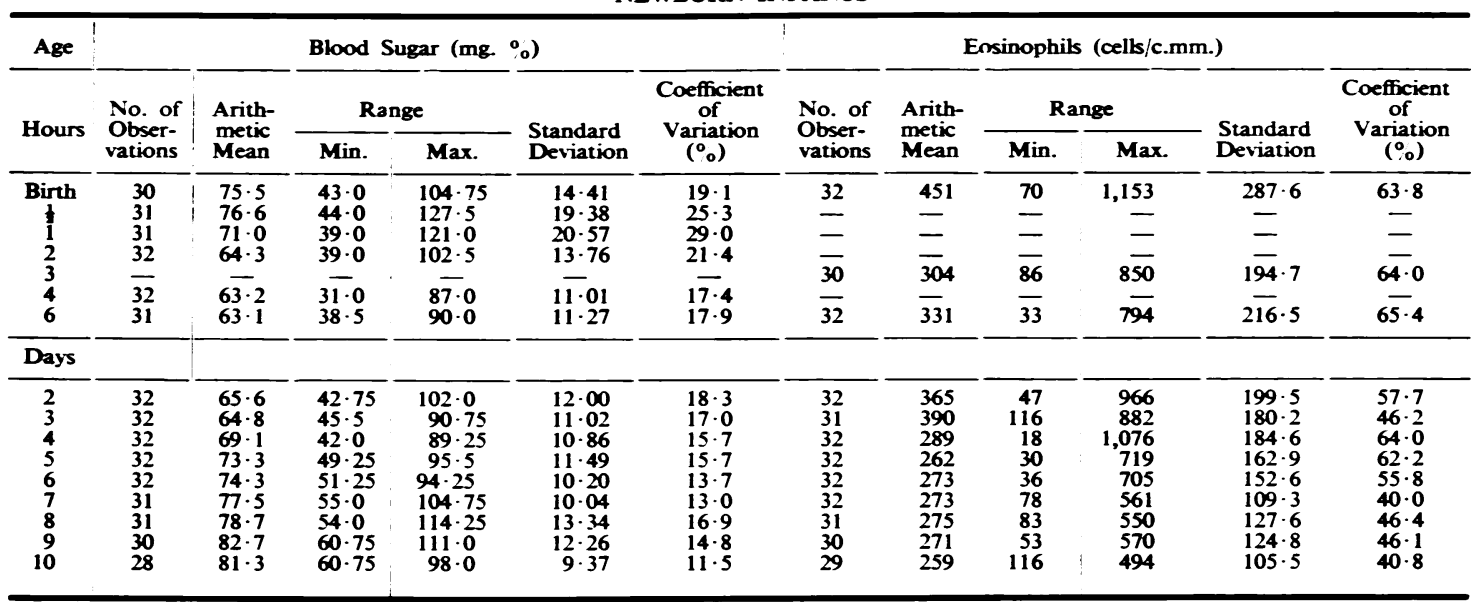


deficient in the immediate newborn period and probably normal by the second week.

So far, then, as functional studies of the adrenal cortex have gone at this age they suggest that after birth there is a period of relative adrenal hypofunction. In view of this and the known part played by the sugar-fat-nitrogen hormone in maintaining the blood glucose level it is of interest that this period corresponds to that on which lowest glucose levels exist.

\section{The Present Investigation}

This study was made to determine whether serial parallel investigations of glucose and eosinophil levels in capillary blood showed simultaneous movement in opposite directions which might suggest from the above argument that each was associated with the adrenocortical changes.

The infants studied were born spontaneously after normal pregnancy, pethidine and gas and air being the only analgesics. All were over $5 \frac{1}{2} \mathrm{lb}$. birth weight and breathed within two minutes. Their course in hospital was uncomplicated and no congenital abnormalities were present.

All specimens were taken personally at 5.30 a.m. in order to avoid disturbing the feeding routine which would have been occasioned had specimens been taken later. The infants had fasted eight hours. Glucose determinations were made personally in duplicate by the method of Ramsay (1950). The method has the advantage to the paediatrician that duplicate analyses may be made on $0.1 \mathrm{ml}$. (as in this investigation) although the method is sufficiently sensitive to allow a single estimation on $0.02 \mathrm{ml}$. of blood. The method is straightforward and the final colour is stable provided it is shielded from sunlight. Errors, however, are readily introduced by contamination of apparatus and cleaning must be scrupulous.

In this study, the accuracy of the method was tested before beginning the investigation, and was found to be extremely good. Three sets of 12
SERIAL BLOOO SUGAR LEVELS OF 32 NORMAL FULL TERM

NEWBORN INFANTS
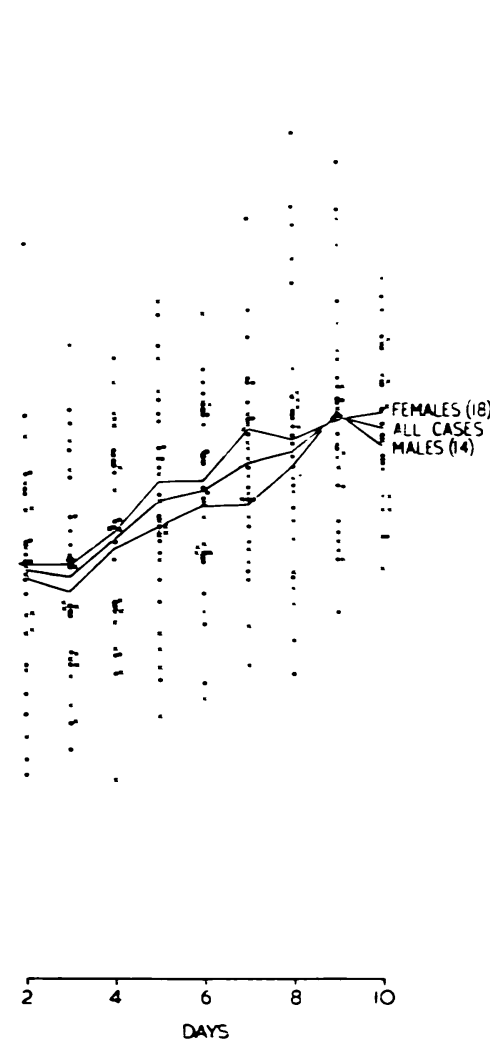

DAYS

\begin{abstract}
showing scatter on each day.
\end{abstract}
readings (six duplicate analyses) at various known concentrations of glucose were analysed; the result gave a very small scatter even in the very dilute solution ( $25 \mathrm{mg} . \%)$. The highest scatter in any set of 12 gave a standard deviation of only $1 \cdot 8 \%$ of the mean. The same standard of accuracy was maintained throughout the investigation, frequent checks being made against glucose standards, and duplicate analyses of the blood specimens were made throughout in order to reduce possible error. Occasionally specimens were lost due to breakage or error while toward the tenth day some cases were lost from the series owing to premature discharge from hospital.

The blood sugar was determined at birth, halfhourly until two hours and then two hourly till six hours. Thereafter it was determined daily until the tenth day.

The eosinophils were counted using the technique modified by Smart (1950) from Randolph's method (McArthur, Smart, MacLachlan, Terry, Harting, 


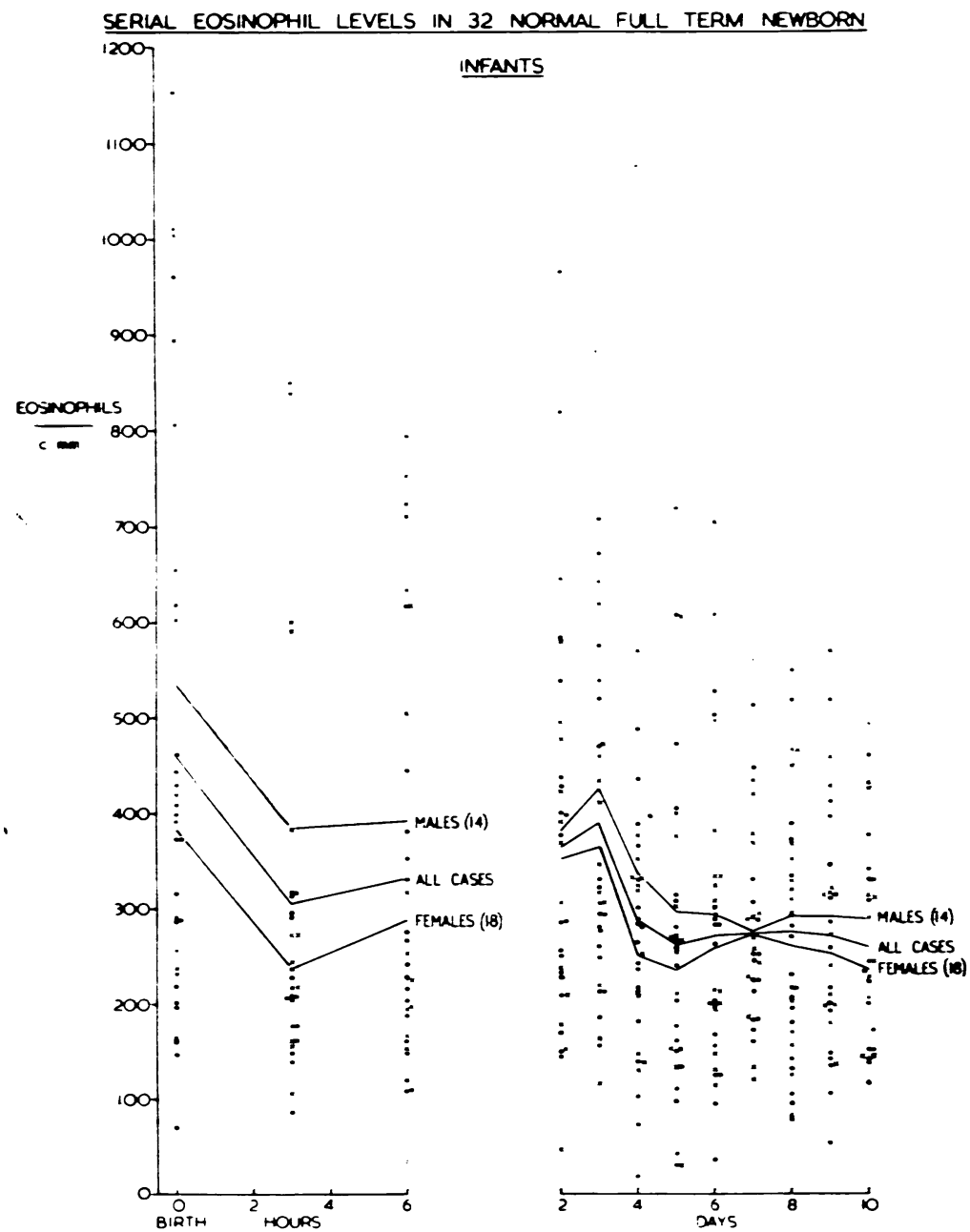

Fig. 3.-Time-trend diagram for eosinophils levels in 32 full-term, newborn infants showing scatter on each day.

Gautier, Godley, Swallow, Simeone, Zygmuntowicz, Christo, Crepeaux, Point and Benson (1954). The diluent consisted of equal parts of an $0.05 \%$ aqueous solution of phloxine and of propylene glycol. Blood was taken in one pipette and was carefully mixed; the total number of cells in four Fuchs-Rosenthal chambers was counted.

\section{Results}

Of the 32 infants in the series 18 chanced to be females. The blood sugar and eosinophil readings were submitted to statistical analysis not only of average figures for each feature but also of the concomitant trend of the two features in each individual child; this was done not only for the actual readings at each age but for the day-to-day changes in readings throughout the study. The methods of analysis are described in the Appendix.

\section{The Group Described Collectively}

At Each Day. The average values for blood sugar readings and eosinophil counts were studied in various ways. The standard deviations and coefficients of variation were calculated for each feature for each time unit (Table 2).

Taking the immediate birth period first it may be seen from the time-trend diagrams (Figs. 2 and 3) and from Table 2 that the mean blood sugar level for the group as a whole fell rapidly during the first two hours of life and that this was arrested before a similar period of time had elapsed: that is, the average blood sugar for the group fell by $11.2 \mathrm{mg}$. in the first two hours, by $1.1 \mathrm{mg}$. in the following two hours and by $0.1 \mathrm{mg}$. only in the next two hours. Similarly in the group as a whole the mean of circulating eosinophils fell by 156 during the first three hours of life and then rose by 27 cells/c.mm. in the next three hours, a considerably smaller increase.

In the next period, from the second to tenth days, the mean blood sugar level for the group as a whole increased steadily from $65.5 \mathrm{mg}$. $\%$ on the second to $82.7 \mathrm{mg} . \%$ on the ninth and $81.3 \mathrm{mg}$. $\%$ on the tenth day. Over the same period the group average value of the eosinophil levels decreased from 390 cells/c.mm. on the third day to 259 cells/c.mm. on the tenth but this fall took place largely from day three to four.

Mean values cannot be taken as adequate descriptions and in this series particularly the scatter of values around the group mean at any time unit for both blood sugars and eosinophils was great. This can be seen both from the time-trend diagrams, which illustrate also the daily scatter of the actual 
observations, and from the coefficients of variation in Table 2. In the blood sugar the coefficient of variation ( $=\mathrm{S}$.D. $/$ mean expressed as a percentage) rose from $19 \%$ to $29 \%$ in the first hour and settled with some fluctuations thereafter to $12 \%$. This is a high coefficient of variation. For eosinophils the scatter of values around the group mean was very much greater, the coefficient of variation starting above $60 \%$ and fluctuating widely above $40 \%$ even towards the tenth day.

Day-to-day Mean Increments. Although the scatter of actual values on individual days decreased slightly, suggesting stabilization, the actual scatter of increments of individual infants from day to day did not decrease.

\section{Components of the Group}

Time-mits. Although the group mean for blood sugar tended to rise daily from the third day and over the same interval the group mean for eosinophils tended to fall; this was not accepted as reflecting the behaviour of individuals within the group. So great was the daily scatter of readings, particularly for eosinophil values, that more detailed analysis of this behaviour was considered essential, for many individuals within the group could have had rising eosinophils even though the group mean fell slightly.

The component 'paired readings' of blood sugar and eosinophil counts for each child at each time unit to some extent explain this wide scatter. The relationship existing between the blood sugar and eosinophils for each infant on each day was found from the correlations (see Appendix) and is also illustrated in the scatter diagrams (e.g., day 3, Fig. 4, and day 6, Fig. 5).

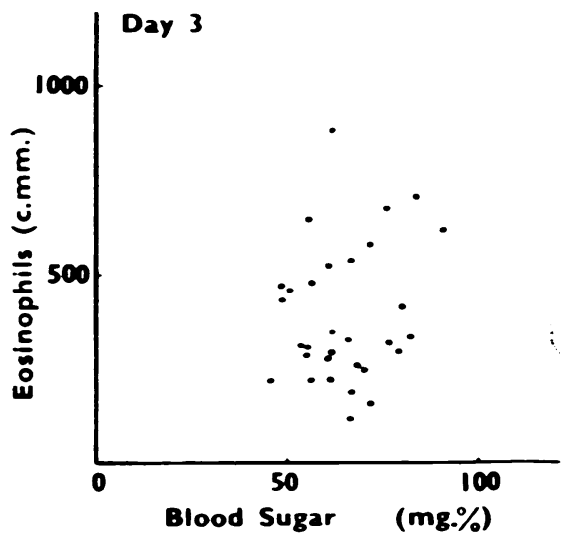

Fvo. 4.-Scatter diagram of cosinophils against blood sugar values on day 3.
It is clear from these that the eosinophil levels were not lower in those infants who had higher blood sugars. On some days the visual impression appears to indicate that those infants with higher sugar values tended to have higher eosinophil levels. On most days even this visual impression is absent.

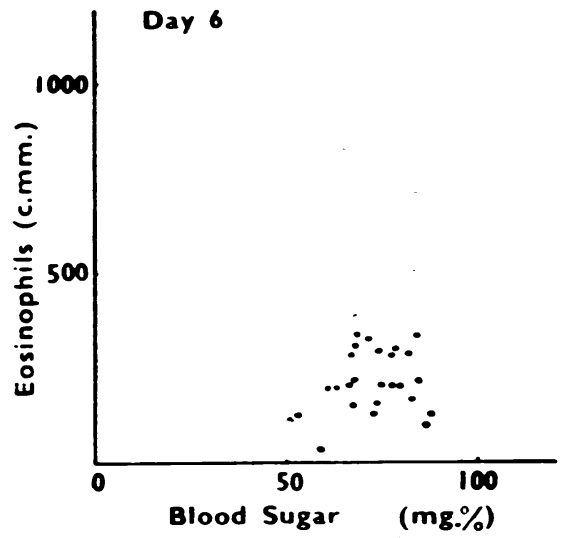

FiG. 5.-Scatter diagram of cosinophils against blood sugar values on day 6.

Increments. The calculation of the correlation coefficients in fact shows that there was no relation ship whatever between the changes in blood sugap and the changes in eosinophils; on some days there was a small positive correlation and on others a negative, as detailed in the Appendix.

\section{The Individual Child}

Though there was no relationship between the two features on any day or between one day and the next, it might still be possible for each child to have falling eosinophils and rising blood sugars, each having its own cycle, and the phase in any individual not necessarily corresponding in time with the same phase in another individual. Graphs were therefore drawn for each individual showing the changes in both features. It then became apparent that the following patterns of movement existed for individuals within the group: $A$, blood sugar and eosinophil movement fairly consistently in opposite directions (Fig. 6); B, an upward trend for both blood sugar and eosinophils (Fig. 7); C, level blood sugar trend and downward trend for eosinophils (Fig. 8); D, no eosinophil trend while blood sugars increased (Fig. 9); E, blood sugar increased, eosinophils decreased but not simultaneously or consistently in opposite directions (Fig. 10).

In five individuals of the 32 in the group, the 


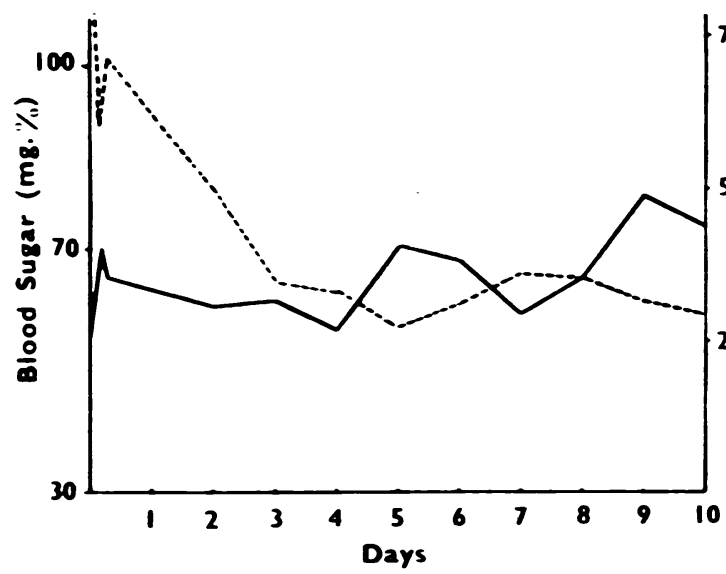

Fio. 6.

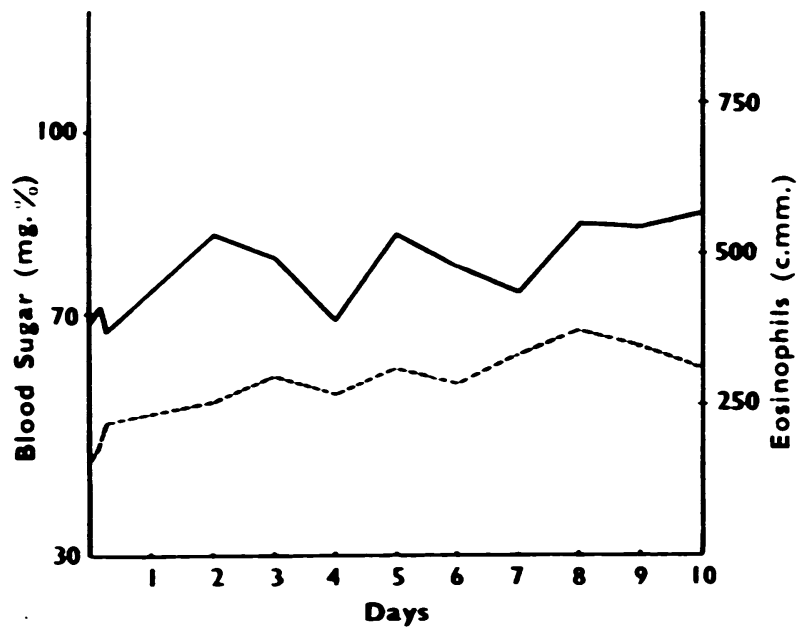

Fig. 7.

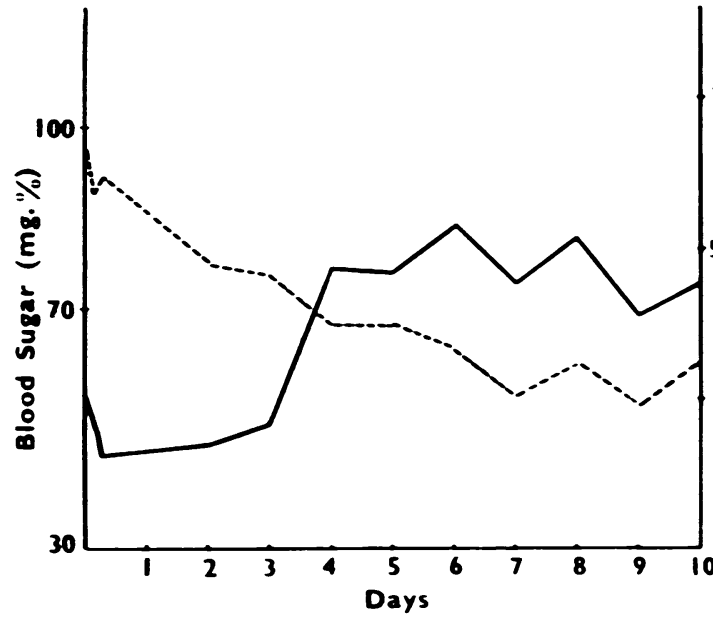

Fig. 8.

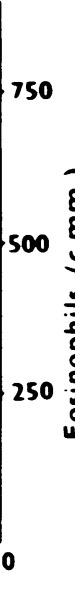

250

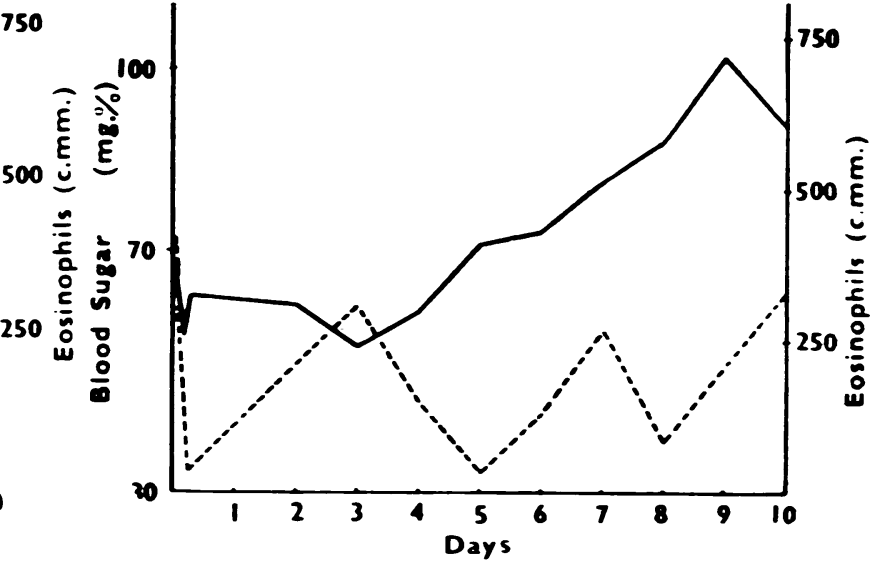

Frg. 9.

Fics 6-10.-Patterns of blood sugar and cosinophil movement. Unbroken line represents blood sugar value. Broken line represents cosinophil count.

Fig. 6-Pattern A. Fairly consistently in opposite directions.

Fig. 7.-Pattern B. Upward trend for both blood sugar and cosinophik.

Fig. 8.-Pattern C. Blood sugar trend level, cosinophil trend downwards.

Fig. 9.-Pattern D. Blood sugar increases, no cosinophil trend.

Fig. 10.-Pattern E. Blood sugar increases, cosinophil count decreases; movement not consistently in opposite directions.

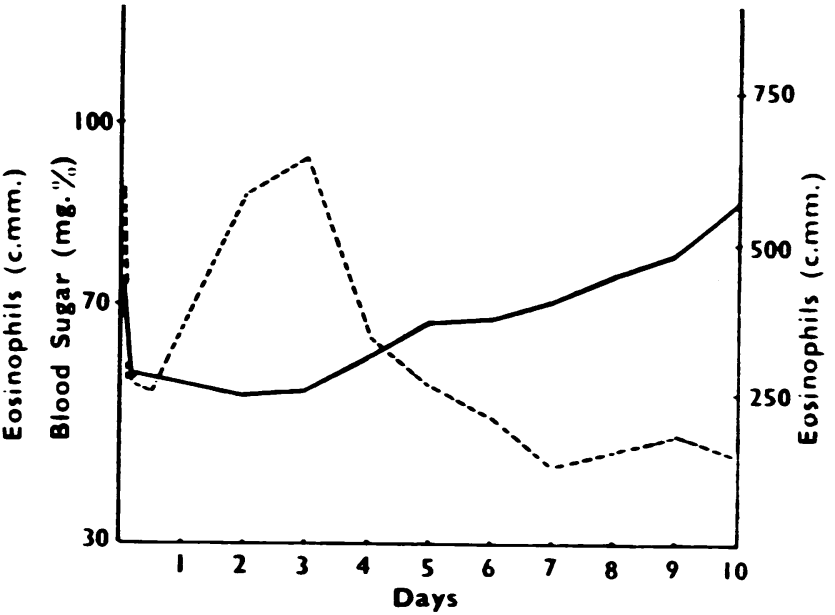

Fig. 10. 
day-to-day graphs of the two features formed a pattern of opposite movement of type $A$, in nine both features rose as in $B$, in two the blood sugar was level and the eosinophils decreased as in C, in 11 there was no trend for eosinophils although the blood sugars increased as in $\mathrm{D}$, and in five the blood sugars increased and the eosinophils decreased as in $\mathbf{E}$.

Five infants only of the 32 studied produced a pattern of simultaneous movement in opposite directions. The largest single group of individuals, 11 , had widely varying eosinophil levels from day to day which conformed to no pattern at all but were associated with rising blood sugar values. The majority of infants showed an upward trend of blood sugars, and, although the eosinophil pattern was more erratic, six infants had particularly high levels at birth and another five such very high levels on the third day that they dominated the means. This helps to explain why a study of the means alone gives the impression of increasing blood sugar and decreasing eosinophils.

It is clear from this individual analysis that simultaneous movement in opposite directions did not often occur.

\section{Discussion}

A number of theories, mostly relating to the function of the liver, have been elaborated to explain the hypoglycaemia of newborn infants and these have been reviewed by Smith (1951) and by Pedersen (1952). van Creveld (1929), investigating the blood glucose levels of premature infants, suggested that hepatic immaturity was responsible, for with progressive maturation the levels rise. That the liver is immature in its function in both premature and in the majority of full-term infants has been shown in a variety of ways and more recently by Mollison (1948) but why it should be responsible for hypoglycaemia is far from plain. It is true that the lowest post-natal levels correspond roughly to the days of weight loss and of minimal calorie intake but the newborn infant is born with an adequate glycogen store in the liver which is built up during the last trimester (Windle, 1940). This means that the low blood sugar levels are not due initially to lack of glycogen as suggested by van Creveld (1929) when he spoke of glucose from the placenta bypassing the foetal liver via the ductus venosus. Ward (1953) suggested that the glycogen was used quite quickly in starvation, but the cases studied were few and the duration of pregnancy and birth weights very varied.

There is no question of adrenalin deficiency in newborn babies (West, Shepherd, Hunter and
MacGregor, 1953) and although it has been suggested that because of hepatic immaturity glycogenolysis does not result from adrenalin secretion the work of Desmond, Hild and Gast (1950) has shown that the sugar level does rise when adrenalin is injected at any time from birth although it is true that flatter curves occur in the first few days than later.

The possibility of the foetal pancreas producing an excess amount of insulin has been raised and there is controversy as to whether or not functional over-activity exists. Nakamura (1924) described an excess of islet cells in foetuses and newborn infants, while Fisher and Scott (1934) found pancreatic insulin levels in the newborn calf higher than in the adult animal. Köhler (1932) and Ketteringham and Austin (1939) applied this to human infants and ascribed the hypoglycaemic levels to true insulin hypersecretion.

Winter (1933) opposed the suggestion of excessive insulin on the grounds that the post-natal blood sugar was rising at a time when the pancreas was unchanged but this assumes that the function of a normal endocrine gland is necessarily reflected in the histology of those who die. White (1949) discarded the idea of hyperinsulinism as the mechanism of hypoglycaemia in the infants of diabetics because in her view such a process should inevitably be continuous and should eventually produce a zero value. Such an argument would also apply to the normal were hyperinsulinism a fact and were no other mechanism to intervene. Hartmann and Jaudon (1937) believed the cause to be relative hyperinsulinism, without necessarily hyperplastic $\beta$ cells, there being incomplete development of opposing mechanisms; while Wachter (1949) speaks of an absolute hypersensitivity to insulin in the first few days of life. The latter found that adrenalin was capable of producing a normal rise at this age, but if insulin were previously injected then no such rise occurred, a phenomenon confined to this age group. No explanation of the hypersensitivity was offered.

Soskin (1941) and Soskin and Levine (1946) believed the fasting blood sugar at any age to be identical with the hepatic threshold for glucose; above the threshold liver glycogenesis occurs and below it there is liver glycogenolysis. The hepatic threshold in turn is determined by hormonal activity, insulin lowering it and anterior pituitary hormone producing a rise. Pedersen (1952) believed the blood glucose level on the first day of life in normal infants and in the offspring of diabetic women to be explicable on this basis. The foetal level in utero is thus determined by the maternal and in turn dictates the foetal output of insulin. The 
latter is responsible for the foetal liver threshold so that the higher the maternal level the lower the foetal threshold and the more profound the glucose levels in the first 24 hours. Similarly low maternal levels result in a low foetal output of insulin, a high foetal liver threshold and higher levels on the first day of extra-uterine existence.

Such a theory has much to commend it but takes no cognizance of the pituitary-adrenal axis which plays such a big part in carbohydrate metabolism and which varies so much at this age.

The stress of pregnancy does seem to result in increased activity in the maternal pituitary and adrenal glands, particularly in the latter weeks, and the cortisone output in the maternal urine from the eighth month is raised, the range in normal pregnancy being the same as that found in cases of medical stress (Cope, Boysen and McCrae, 1951). Similar results were previously found by Venning (1945).

The following hypothesis was elaborated from a study of the literature, and the investigations described in this paper were undertaken to shed light upon it. The increased maternal corticotrophin crosses the placenta, stimulates the infant's adrenals, produces the well-known foetal reticular zone and, with placental diffusion of glucose, the foetal liver threshold is set high. The upward trend of foetal blood glucose stimulates the pancreas so that the production of insulin may indeed exceed that existing in later life.

When the cord is clamped, the maternal source of sugar supply is no longer available and foetal glucose levels begin to fall, insulin producing hepatic glycogenesis. It is possible that the increasing output of maternal corticotrophin in labour results in some spill-over to the foetus; but the great physiological stress of adaptation to extra-uterine life, with its problems of respiration and thermal independence, provides stimulation for the endogenous production of corticotrophin, and this in turn results in secretion of the sugar-fat-nitrogen hormone. Resulting economy in tissue oxidation and gluconeogenesis with the diminishing stimulation to insulin production and possibly release of the hormone of the adrenal medulla account for the arrest of the falling blood sugar values. In some cases the pituitary-adrenal axis may be stimulated by stress before birth, as in asphyxia, and may be present at birth with raised or rising sugar values (Miller, 1941) in the alarm hyperglycaemia described by Selye (1946a). Following this maximal effort in the normal infant there may be a slight further fall until about the third day. This would be consistent with the description by Selye (1946b) of blood sugar changes in animals exposed to stress in which there is a rise in the shock phase followed however by a fall and then a progressive rise in the stage of 'countershock'. The newborn infant differs from the experimental animal in that production of insulin may be above normal. Following the third day the pituitary adrenal axis is firmly established, eosinophils begin to fall again, corticoid excretion increases, there is consequently a progressive rise in the hepatic threshold and a parallel rise in the fasting blood sugar level.

Somewhat similar possibilities occurred to Klein and Hanson (1950) who considered that lack of corticotrophin in the infant might be related to neonatal hypoglycaemia, and to Talbot et al. (1952) who, discussing low corticoid excretion in the first week of life, state:

'It remains to be determined whether the tendency of infants to have relative eosinophilia, to develop hypoglycaemia and to show involution of the foetal zone of their adrenal cortices during the neonatal period, is significantly related to the foregoing.'

It was hoped that confirmation of the above hypothesis might have been obtained from the present study. But statistical analysis has shown that the trend of the group averages, which might have been misconstrued as confirmatory, was of no use whatsoever in depicting individual trends; and other methods of examination of the values have also shown that no simultaneous movement in opposite directions occurred.

The eosinophil count, however, is no substitute for direct estimation of 11-17 oxycorticosteroids; and it is felt that the experiment may have failed to prove, or entirely to disprove, its point because of the weakness of this method of estimating adrenocortical function. When serial estimations of sugar-fat-nitrogen levels are possible in small infants they may throw further light on the relationship between changes in the neonatal adrenal and the chemical hypoglycaemia.

\section{Summary and Conclusions}

The present knowledge of carbohydrate control, of the neonatal adrenal, and of hypoglycaemia in the newborn is briefly reviewed, and an attempt made to link the latter with the anatomical and functional changes in the adrenal gland at this age. Evidence in favour of such a linkage would have been obtained had it been possible to show that simultaneous movement of blood sugar levels and eosinophil counts in normal newborn infants occurred in opposite directions. 
Serial studies of blood sugar levels and eosinophil counts were carried out in a group of 32 normal infants.

Previous work on the neonatal blood sugar levels is open to some criticism but it was confirmed that the variation between individuals at any time unit was wide and also that considerable variation occurred in individual infants at each time interval.

This scatter of individual values at any time unit was so great as to render the arithmetic mean of the group valueless as representing the behaviour of individuals.

The blood sugar level tended to fall fairly rapidly in the first hours after birth but was stabilized by about four hours. It remained as an impression that those individuals in whom the blood sugar rose immediately after birth were those who approached more closely to the two minutes accepted as the upper limit of normal before respiration was established.

An upward trend in blood sugar values over the 10-day period occurred in the majority.

From scatter diagrams, not reproduced here, there was no correlation between body weight and the blood sugar level.

The eosinophil levels of the group were appreciably higher than in adults.

The scatter of eosinophil counts between individuals was great at any time unit and also in the same individual at any time interval. As with blood sugar this scatter was sufficiently great to invalidate the group mean as a representation of individual behaviour.

Twenty-six of the infants showed a fall in eosinophils, many of them a substantial fall, in the first few hours.

The relationship between the blood sugar level and eosinophil count was studied in individual cases and five distinct patterns found. These showed that the pattern of inverse movement of the means of the two features was false. The mean blood sugar level rose steadily from the third to the tenth day whereas the fall in the mean eosinophil level took place largely between the third and fourth day. Comparison of the change in mean values was therefore impossible over the same time interval.

When the behaviour of individuals was studied it was clear that simultaneous movement of blood sugar values and eosinophil counts in opposite directions did not take place but it remains possible that direct measurement of the sugar-fat-nitrogen hormone production would show a relationship between a period of adrenocortical hypofunction and hypoglycaemia.
I wish to record my gratitude to Professor R. W. B. Ellis for his encouragement and advice and for permission to work in the nurseries under his care; to Dr. E. C. Fahmy and Professor R. J. Keller for permission to work in their units and to the latter for generous laboratory facilities; to Professor G. F. Marrian and Dr. W. N. M. Ramsay for advice on biochemical methods and other matters; to the nursing staff of the Simpson Memorial Maternity Pavilion for their cooperation and to my wife whose assistance made the investigation possible. The work was carried out during the tenure of the George Guthrie Research Fellowship of the University of Edinburgh.

\section{BIBLOGRAPHY}

Blackman, S. (1946). Bull. Johns Hopk. Hosp., 78, 180

Burrell, J. M. (1953). Archives of Disease in Childhood, 28, 140.

Clatworthy, H. W. and Anderson, R. G. (1944). Amer. J. Dis. Child., 67, 167.

Cope, C. L., Boysen, X. and McCrae, S. (1951). Brit. med. J., 2762 .

Creery, R. D. G. and Parkinson, T. J. (1953). Archives of Disease in Childhood, 28, 134.

Creveld. S. van. (1929). Amer. J. Dis. Child., 38, 912.

Day, E. (1948). Med. J. Aust., $2,122$.

Desmond, M. M., Hild, J. R. and Gast, J. H. (1950). J. Pediat., 37,341 .

Fisher, A. M. and Scott, D. A. (1934). J. biol. Chem., 106, 305.

Forkner, C. E. (1929). Bull. Johns Hopk. Hosp., 45, 75.

Gersh, I. and Grollman, A. (1939). Amer. J. Physiol., 126, 368.

Grollman, A. (1936). The Adrenals. London.

Hartmann, A. F. and Jaudon, J. C. (1937). J. Pediat., 11, 1.

Hilk, A. G., Forsham, P. H. and Finch, C. A. (1948). Blood, 3,

Howard, E. (1937). Amer. J. Physid., 119, 339.

Ketteringham, R. C. and Austin, B. R. (1939). Amer. J. Obstet. Gynec., 37, 1000.

King, E. J. and Garner, R. J. (1947). J. clin. Path., 1, 30

Klein, R. (1950). Proc. ist Clinical ACTH Conference. London. (1951). 2nd Clinical ACTH Conference, Vol. 1, chapter 14. London.
and Hanson, J. (1950). Pediatrics, 6. 192.

Fortunato, J. and Papadatos, C. (1954). J. clin. Invest., 33,35 .

Köhler, A. (1932). Arch. Gynäk., 149, 421.

Komrower, G. M. (1954). Archives of Disease in Childhood, 29, 28.

Lehmann, H. and Silk, E. (1952). Biochem. J., 50, xxxi.

Long, C. N. H. (1952). Lancet, 1, 325.

McArthur, J. W., Smart, G. A., MacLachlan, E. A., Terry, M. L., Harting, D., Gautier, E., Godley, A., Swallow, K. A., Simeone, F. A., Zygmuntowicz, A., Christo, E., Crepeaux, J., Point, W. W. and Benson, J. A.'(1954). J. clin. Invest., 33, 420 .

McKittrick, J. B. (1940). J. Pediat., 16, 151.

McNeill, M. (1947). Ulster med. J., 16, 41.

Miller, R. A. (1941). Archives of Disease in Childhood, 16, 113.

Mollison, P. L. (1948). Lancet, 1, 513.

Nakamura, N. (1924). Virchow's Arch. path Anat., 253. 286.

Norval, M. A., Kennedy, R. L. J. and Berkson, J. (1949). J. Pediat., 34. 342 .

O'Donnell, W. M., Fajans, S. S. and Weinbaum, J. G. (1951). Arch. intern. Med., 88, 28.

Pedersen, J. (1952). Diabetes and Pregnancy: Blood Sugar of Newborn Infants during Fasting and Glucose Administration. Copenhagen. Potter, E. L. (1952). Pathology of the Fetus and the Newborn.
Chicago.

Ramsay. W. N. M. (1950). Biochem. J., 47, xli.

Reichstein, T. (1936). Helv. chim. Acta, 19, 223

Reis, R. A. De Costa, E. J., and Allweiss, M. D. (1950). Amer. J. Obstet. Gynec., 60, 1023.

Sayers, G. and Sayers, M. A. (1948). Recent. Progr. Hormone Res., 2.81. J. Bio. Mry, E. G., White,

Selye, H. (1946a). J. Allergy, 17, 292

Selye, (1946b). J. clin. Endocr., 6, 117.

(1949). Textbook of Endocrinology, 2nd ed. Montreal.

Smart, G. A. (1950). Personal communication.

Smith, C. A. (1951). The Physiology of the Newborn Infant, 2nd ed. Oxford.

Soskin, S. (1941). Physiol. Rev., 21. 140.

- and Levine, R. (1946). Carbohydrate Metabolism. Chicago. Svensgaard. E. (1931-32). Acta paediat., Uppsala, 12. Suppl. 4.

Swinyard, C. A. (1943). Anat. Rec., 87, 141.

Zygmuntowicz, A. N., Wood, $M$. and Christo, E. (1950). Proc. 1st Clin. ACTH Conference, p. 32. London. 
Talbot, N. B., Sobel, E. H., McArthur, J. W. and Crawford, J. D. (1952). Functional Endocrinology, Cambridge, Mass.

Thorn, G., Forsham, P., Prunty, F. T. G. and Hills, A. G. (1948). J. Amer. med. Ass., 137, 1005.

Venning, E. (1945). Transactions of Tenth Conference on Metabolic Aspects of Convalescence, p. 177 . Josiah Macy Jr. FoundaAspects of Con

tion, New York.
Wachter. Hin. A Proc. Ist Clin. ACTH Conference, p. 25. London.

Wachter, H. E. (1949). J. Mo. med. Ass., 46. 837 .
Ward, O. C. (1953). Archives of Disease in Childhood, 28, 194.

Weltmann, O. (1913). Beitr. path. Anat., 56, 278.

West, G. B. Shepherd, D. M., Hunter, R. B. and MacGregor, A. R. (1953). Clin. Sci., 12, 317.

White, P. (1949). Amer. J. Med., 7, 609.

Windle, W. F. (1940). Physiology of the Fetus. Philadelphia.

Winter, E. W. (1933). Arch. Gynäk., 154, 354.

Wootton, I. D. P. and King, E. J. (1953). Lancet, 1, 470.

\title{
A P P E N D I X
}

\section{SUMMARY OF STATISTICAL METHOD}

\author{
BY \\ LILLI STEIN \\ From the Department of Social Medicine University of Edinburgh
}

The analyses of the serial observations of blood sugars and eosinophils were directed first to the description of the levels found in these newborn infants in order to establish a standard with which other infants might be compared, and secondly to the examination of the hypothesis that in the newborn infant the change in blood sugar is synchronous with but, in the opposite direction to, the change in circulating eosinophils. Descriptions consisted of means, standard deviations from means, coefficients of variation and sampling errors of means, for males and females separately as well as for the group as a whole. In addition, correlation coefficients between blood sugar and eosinophil levels in the same infant were calculated for each age, and also for the day-to-day changes from the first day to the tenth and for the change between levels in the interval sixth to tenth day.

\section{Group Descriptions at Each Age}

Blood Sugar Levels at Each Age. The variability of the readings around the mean was considerable at each age, and there was little regularity either for males or for females; even at the later ages, the range of normality was from $30 \%$ to $50 \%$ higher or lower than the mean. There was no significant difference between the sexes; the slightly higher blood sugar means for females than for males were well within the range of chance occurrence. The sampling errors of the means were too high to define the mean as a reliable index for the group. The results indicated that the means could not be taken as definite standards either for the purpose of defining normal children or for the purpose of comparison with other groups of infants. It appeared that blood sugar in the individual infant was too variable a character to constitute a satisfactory index of adrenal function during the first 10 days of life.

Circulating Eosinophils at Each Age. The impression of a falling trend in the group mean was not confirmed by the trends of the male and female means separately; for males alone the means tended to rise in the later days. However, standard deviations and sampling errors of means were so great that no precise trend in eosinophil levels in the individual could be deduced, and the normal range on any day could have been from zero to more than double the mean. The differences between male and female means were not significant. The tremendous fluctuations in daily eosinophil levels in each child indicate that this character cannot be used as an index of the infant's functional response in the first 10 days of life, and that the group means cannot be taken as definite standards for purposes of comparison.

Day-to-Day Changes. It has already been noted that, although after the third day the group means of blood sugar and eosinophil levels appeared to move steadily, the means for males and females separately did not show any consistent day-to-day trend. The explanation of this apparent inconsistency can be found in the standard deviations of the individual increments, which were so great that, during each time-interval, large decreases in blood sugars were just as much within the range of normality as large increases. The scatter of the day-today increments was even greater for eosinophils than for blood sugar.

This variability in changes from one day to the next might be thought to conceal a steady trend which would emerge if a longer interval were studied. However, for the four-day period from the sixth to the tenth day the variability was just as apparent (Fig. 11); both for blood sugar and for eosinophils large decreases and increases fell within the normal range. These results indicate that the means of day-to-day changes cannot be taken as definite standards for the purpose of defining normal children or for the prediction of expectation in the trend of blood sugar or eosinophil levels.

\section{Group Components: Correlation between Błood Sugar and Eosinophils}

It is often assumed that the time-trend of a group mean can be taken as representing also the time-trend in the individual. That this is not justified when the character is very widely scattered in the population has already been illustrated above; for the purpose of treating an infant and for prediction for the individual it is necessary to 
know the extent of correlation between the two characters in the individual child. In the present series of newborn infants, the correlations between blood sugar and relationship whatever. Many of the correlations were positive though not significant, and the negative correlations which did occur were quite insignificant. Over the

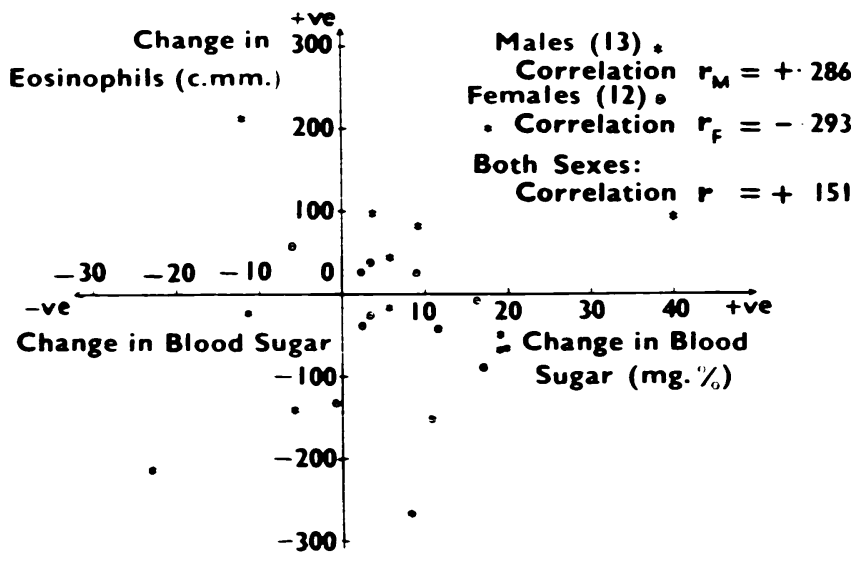

FiG. 11.-Graph showing blood sugar change against eosinophil change for the period day 6 to day 10 .

eosinophil levels were not significant, being mostly extremely small. Moreover, most of the coefficients were positive-whereas, if there had been an inverse relationship of high blood sugar to low eosinophil levels, one would expect to get negative correlations fairly consistently. The few negative correlations which occurred in one sex were on days when for the other sex the correlation was positive. The conclusion must be that there was no consistent relationship between the levels of blood sugar and eosinophils in the individual infant on any day up to the tenth.

It might be thought that, nevertheless, the direction of change in blood sugars was inversely related to the direction of eosinophil change. From the correlation coefficients between blood sugar and eosinophil day-today changes, it was evident that there was in fact no four-day period, when trends in individual infants might have become more stable, the correlation between blood sugar increases and eosinophil increases was actually positive for the group taken as a whole, though it was negative for the females taken alone. This can be seen in Fig. 11, in which is illustrated the individual infant's blood-sugar change against his or her eosinophil change. During this four-day interval, four males and seven females had an increase in blood sugar accompanied by a decrease in eosinophils, and one male and one female had a decrease in blood sugar accompanied by an increase in eosinophils. On the other hand, five males and three females had an increase in both characters, whilst three males and one female had a decrease in both. Thus it appears that, even over a longer period than one day, no relationship could be found between blood sugar and eosinophil trends during the first ten days of life.

\section{Conclusion}

The very detailed analyses of the serial readings of blood sugars and eosinophils, both for daily levels and for day-to-day changes, were undertaken in order to scrutinize most closely the hypothesis that in a newborn baby (after the first few hours) there would be a rise in blood sugar and a fall in eosinophils. No such relationship was found. This failure may well be due to the unreliable index represented by the circulating eosinophils, whose day-to-day fluctuations have been shown to be so great that their mean values have little meaning. These statistical findings do not prove that the hypothesis is mistaken; we state only that we have been unable to find any evidence in its support. 